\title{
Environmental Knowledge among Aboriginal Students
}

\author{
Norshariani Abd Rahman
}

National University of Malaysia yaniey_84@yahoo.com

\section{Lilia Halim}

National University of Malaysia

lilia@ukm.my

\section{Abdul Razaq Ahmad}

National University of Malaysia razaq@ukm.my

\section{Doi:10.5901/jesr.2014.v4n6p279}

\begin{abstract}
This research aims to investigate the level and differences of environmental general knowledge and environmental action knowledge among the Aboriginal students based on level of education, gender and tribe. This survey research used a test as the research instrument. A total number of 445 Aboriginal students from Pahang, Malaysia took part in this study. The research findings showed that as overall their environmental knowledge is good. However, a separate analysis showed that their environmental general knowledge is moderate and their environmental action knowledge is good. When analysed from the perspective of level of education, the level of environmental general knowledge of secondary school students was higher than the primary school students. The students of the Proto Malay tribe showed a higher level of environmental general knowledge and environmental action knowledge compared to students of Senoi and Negrito tribe. Nonetheless, the level of environmental knowledge of male students and female students are just the same. Improvement environmental knowledge should be considered in planning the educational development of Aboriginal community towards environmental sustainability.
\end{abstract}

Keywords: Environmental Education, Aboriginal Students, Environmental General Knowledge, Environmental Action Knowledge

\section{Introduction}

The current community is still not able to manage the environment responsibly leading to many environmental issues and problems. The human being is getting greedier in exploiting the nature without having a second thought about the next generation that will cause the destruction of the natural resources and imbalance. Environmental problems such as the extinction of certain flora and fauna, landslide, global warming, thinning of the ozone layer, haze, air, river and sea pollution prove the impact of negative human behaviour towards the environment.

Ethical behaviour is one of the most important aspects that should be possessed by an individual in sustaining the quality of environment parallel with the country's development (Hungerford et al. 2005). Therefore, many steps have been taken to increase the knowledge, awareness and behaviour towards nurturing the environment not only locally but also globally. At the local level, the concern of government towards the environmental issues is cultivated in the nation's development plan and government policies. This can be further proven by the embodiment of the National Environmental Policy in the year of 2002 which holds on to eight principles to harmonize the aim of economic development and the importance of the environment (Department of Environment 2007).

At the global level, a number of international conference series have been conducted to discuss the environmental issues. Among these conferences are Belgrade, Tbilisi and Earth Summit conferences (Palmer 1998). The main objective of these conferences is to produce citizens who are environmentally literate by having the knowledge, awareness, attitude, skills and positive behaviour towards the nurturing of the environment (Hungerford et al. 2005; Palmer 1998). Following these conferences, the Environmental Education was introduced to cultivate the awareness of environmental care (Hungerford et al. 2005; Mohd. Yusop et al. 2003; Palmer 1998; Stapp 1969). 
The Environmental Education applies to all individuals regardless of their background (Hungerford \& Volk 1990) to create individuals who are knowledgeable, have awareness and responsible behaviour towards the environment. Thus, the Aboriginal community is not an exception in receiving the Environmental Education and play an important role in the environmental sustainability (United Nation 1992). This is due to the fact that the Aboriginal community is known to be the closest with the environment (Chopil \& Hunt 2009; Lim 1997; Nicholas \& Lasimbang 2004; Norjan et al. 2005; Zalizan et al. 2009).

The way of life of Aboriginal people in the past which depended mostly on the natural resources made them live in harmony with the environment (Lim 1997). But, due to development, most of the young generation of Aboriginal people no longer lives in the jungle or practice traditional economy by gathering jungle products. They have been grouped in certain places and practice modern agriculture through the help of the government (JHEOA 2009). The success obtained by the Aboriginal community not only involves changes in economic aspect but also socially and their way of thinking had also changed. The lifestyle change experienced by the current Aboriginal community will influence their knowledge and behaviour towards the environmental care (Hines et al. 1986/87; Kollmuss \& Agyeman 2002).

\section{Problem Statement}

The Aboriginal community has a role to play in caring for the sustainability of the environment as stated in the Earth Summit in Rio De Janeiro in the year of 1992 (United Nations 1992). This is because they are the most dependent on the environment for their economic resources for survival (Hood 2012; Lim 1997; Zalizan et al. 2009). Therefore, the Environmental Education for the Aboriginal people should be given adequate attention to avoid exploitation by those with a personal interest. The current modernisation brought changes to the lifestyle and behaviour of the Aboriginal people. In the past, the Aboriginals used natural resources only for personal use. But then again, due to demand of external people and monetary return, they were exploited to commercially gather natural resources such as plants with medicinal and economical values and also exotic animals (Nicholas \& Lasimbang 2004).

Modernisation and development of the Aboriginals have produced the generation of Aboriginals that do not hold strongly to their customs, belief and tradition about the nature as they used to before (Chopil \& Hunt 2009). Among the large scale modernisation and developmental programs of Aboriginals was the Re-Grouping Plan (RGP). Through RGP, the Aboriginals are taught to work in modern agriculture. Lands were given for rubber and oil palm plantation by RISDA and FELCRA, in order to create new income sources for them. The Aboriginals left the traditional agriculture and focused more on the modern agriculture. This caused a decrease in the tradition of passing down the knowledge of environmental management to the next generation (Nicholas \& Lasimbang 2004). The extinction of their traditional culture also became an obstacle in them learning about the environment (Mallen et al. 2009).

The impact of the decrease in knowledge pass-down from the older generation to the new generation caused the younger generation of Aboriginals to have very low knowledge about the environment. This is supported by the study of Norjan et al. (2005) which found that the level of environmental knowledge among the Aboriginal students in seven secondary schools in the districts of Pekan, Rompin and Bera, Pahang is very low. This finding indirectly showed the weakness of Environmental Education cultivation among the Aboriginal students in the aspect of increasing their knowledge. The environmental knowledge is the basis of developing attitude and changing behaviour towards caring for the environment (Elder 2003; Hines et al. 1986/87; Ramsey \& Rickson 1976). However, study of Norjan et al. (2005) focused only on environmental knowledge. Hines et al. (1986/87) and Emmons (1997) stated that in predicting environmentally responsible behaviour, the element of environmental action is also crucial. Therefore, in this research, this element of behaviour selection towards the environment will be included based on the environmental situation to study the level of environmental knowledge of Aboriginal students.

The awareness and interest of Aboriginal students are also lower compared to other races (Sheppard 1995; Quimby et al. 2007). The awareness and interest about the environment resulted from their low environmental knowledge and this will also influence their behaviour towards caring for the environment (Ramsey \& Rickson 1976; Hungerford et al. 2009; Elder 2003). A research by Haliza (2010) about the involvement of Aboriginals in the issues related to environment found that their level of awareness and involvement can be categorised into three groups. The first group consisted of people who are interested or attracted by the environmental issues but not actively involved. The second group consisted of those who are not concerned about the environmental issues but they support the efforts of others in increasing the quality of the environment, and the third group consisted of those who are neutral, where they are minimally concerned about the nature and normally do not care about the environmental issues. Overall, the findings of this study showed that the awareness and involvement of Aboriginal in issues related to the environment is still not 
adequate.

The environmental changes among the Aboriginal, the rising standards of economy and infrastructure provided in their residence area such as water supply, electricity, school, recreational area and communication line such as telephone, internet and mass media will influence the way the Aboriginals think and act. This matter is supported by Hines et al. (1986) and also Kollmuss and Agyeman (2002), by stating that external factors such as environments of family, school, local community, mass media, economy and infrastructure influence an individual's thinking in acting towards the environment.

\section{Research Methodology}

This research is a survey research which uses quantitative data. The research instrument used in this research consists of three (3) parts which are demography of student, environmental general knowledge test and environmental action knowledge test. It is a multiple choice question. Content validity was checked by 3 individuals who are experts in the field of Education and Environmental Education. The pilot study was conducted using a focus group of 6 Aboriginal students to identify the words, terms or sentences that students cannot understand. As for reliability, the value of KuderRichardson $\left(K_{20}\right)$ for environmental general knowledge is approximately .763 and the value of Kuder-Richardson $\left(K R_{20}\right)$ for environmental action knowledge is .820. The sampling was done using the simple random sampling method. The total population of primary school and secondary school Aboriginal students in Pahang is 14,974. Based on the Krejcie and Morgan (1970) sampling table, a total of 445 students are adequate for this study. However, in the inferential data analysis, number of samples involved was 428 because 17 of them were dropped due to outliers data. This research used SPSS (Statistical Package for Social Sciences) Version 20 was used to analyse data.

\section{Research Findings and Discussion}

\subsection{Profile of Research Respondents}

A total of 445 respondents was involved in this research. They represented the Aboriginal students of various levels of education, gender and Aboriginal tribe. Based on the education level, respondents representing the primary schools were 250 and students representing the secondary schools were 195. From the gender aspect, there were more female students, a total of 238, involved compared to only 207 male students in this study. Based on the Aboriginal tribe, there were 197 (44.3\%) respondents representing the Proto Malay tribe, 242 (54.4\%) respondents representing the Senoi tribe and there were $6(1.3 \%)$ representing the Negrito and other tribes. Since the number of respondents representing the Negrito and other tribes was considerably less, for analysis purposes, the Negrito and other tribes were grouped in the same group as students from the Senoi tribe. Table 1 shows the summary of the respondents' profile in this study.

Table 1: Profile of Research Respondents

\begin{tabular}{llcc}
\hline \multicolumn{1}{c}{ Demography } & \multicolumn{1}{c}{ Respondent } & Frequency & Percentage (\%) \\
\hline Level of school & Primary & 250 & 56.2 \\
\multirow{3}{*}{ Gender } & Secondary & 195 & 43.8 \\
\multirow{2}{*}{ Tribe } & Male & 207 & 46.5 \\
& Female & 238 & 53.5 \\
& Proto Malay & 197 & 44.3 \\
& Senoi & 242 & 54.4 \\
& Negrito & 6 & 1.3 \\
\hline
\end{tabular}

\subsection{The Level of Environmental Knowledge among Aboriginal Students}

As a whole, the level of environmental knowledge among Aboriginal students is good with a mean score of $66.49 \%$. However, not all the elements are at that level. The mean score value for the element of environmental knowledge which is $58.79 \%$ showed that their knowledge is at a moderate level, meanwhile the level of environmental action knowledge among the Aboriginal students is good with a mean score of $77.50 \%$. The summary of research finding on the level of environmental knowledge, which are environmental general knowledge and environmental action knowledge, is shown is Table 2 below. 
Table 2: Mean Score of Elements in Environmental Knowledge Construct

\begin{tabular}{lcc}
\hline Element in Environmental Knowledge Construct & Mean Score (\%) & Mean Score Interpretation \\
\hline Environmental Knowledge & 58.79 & Moderate \\
Environmental Action Knowledge & 77.50 & Good \\
\hline Overall Knowledge & 66.49 & Good \\
\hline
\end{tabular}

The level of environmental general knowledge which is at a moderate level is due to two factors based on literature review. The first factor is students already have the indigenous knowledge but do not show interest in learning the concept of environment in school. The second factor is the weaknesses of the students in understanding the concept of science (Norjan et al. 2005). This is because, the question posed in the environmental knowledge tests are mostly related to the Science subject and the students must have the basic in Science education. The finding of this study is a little bit different compared to the research done by Norjan et al. (2005) where her research showed that the environmental knowledge level of the Aboriginal students is low. This showed that there is an increase in the environmental knowledge of Aboriginal students.

A moderate level of environmental general knowledge not necessarily means a moderate level of behavioural knowledge. This is due to the fact that the research findings point that the students have good environmental action knowledge. This further proved that the Aboriginal students knew the good behaviours that should be followed in situations that involve decision-making to reduce environmental problems although they have only moderate environmental knowledge.

\subsection{The Differences of Elements in the Construct of Environmental Knowledge Based on the Level of Education}

MANOVA analysis was done to observe the differences of elements in the construct of environmental knowledge. Prior to the MANOVA analysis, Box' $M$ and Levene tests were done to test the suitability of running a MANOVA analysis. In the MANOVA test, there are a few types of tests to test hypothesis namely Pillai's Trace, Wilks's Lamda, Hotelling's Trace and Roy's Largest Root. These tests are used to look at the Multivariate differences between groups. But then, Hair et al. (2006) and Pallant (2005) suggested using the statistic of Wilks' Lambda since it is more robust for balanced number of samples. Table 3 shows the finding of MANOVA analysis for elemental differences in the construct of environmental knowledge between primary school students and secondary school students. The finding show that there is a significant mean score difference for the construct of environmental knowledge as a whole based on the level of education where the value of Wilks' Lambda $=.939 ; F(2,425)=13.740, p=.000(p<.05)$, and partial eta squared, $\eta^{2}=.061$.

Table 3: MANOVA Analysis of Elemental Differences of Environmental Knowledge Based on the Level of Education

\begin{tabular}{|c|c|c|c|c|c|c|c|}
\hline Group & $\mathbf{N}$ & Wilks' Lambda Value & F Value & Intergroup df & Intragroup df & Sig. Level & Partial $\eta^{2}$ \\
\hline Primary & 240 & .939 & 13.740 & 2 & 425 & $.000^{*}$ & .061 \\
\hline Secondary & 188 & & & & & & \\
\hline
\end{tabular}

*significant at the level of .05

After obtaining the significant result in the multivariate test, further research was done to identify the elements in the construct of environmental knowledge that truly differs based on the level of education. For this purpose, test of betweensubject effects was referred and the analysis showed repeated comparison analysis. To reduce Error Type 1 which is due to repeated analysis, Alpha Bonferroni modification method was used (Hair et al. 1998). Table 4 shows that there is significant difference based on the level of Alpha Bonferroni (.05/2) $=.025$ in the elements of environmental general knowledge between primary school students and secondary school students where the values are $F=27.494, p=.000$, partial eta squared $\left(\mathrm{n}^{2}\right)=.061$. Based on the mean scores for the elements of environmental knowledge found that the mean score for the secondary school students (mean score $=64.84 \%$ ) is higher than the primary school students (mean score $=54.04 \%$ ). This implies that their environmental knowledge increases correspondingly with the age and level of education (Anderson et al. 2007; Kollmuss \& Agyeman 2002). On the other hand, a research by Mallen (2009) showed that environmental knowledge does not have a linear relationship with academic year where second year students were higher compared to third year and first year students. This was because the second year students must take a course related to the environment and the third year students have forgotten what they learnt during their second year. This shows the importance of consistent Environmental Education and it matches the opinion of Hungerford et al. (2005), who 
stated that Environmental Education is a lifelong learning. However, there are no significant differences for the elements of environmental knowledge between primary school students and secondary school students where the values are $F=$ $5.034, p=.109 ;$ partial eta squared $\left(n^{2}\right)=.012$.

Table 4: Intergroup Test Finding of Effect of Level of Education on the Elements in the Construct of Environmental Knowledge

\begin{tabular}{lccc}
\hline Elements in the Construct of Knowledge & F Value & Sig. Level $(\mathbf{p})$ & Partial $\boldsymbol{\eta}^{\mathbf{2}}$ \\
\hline Environmental Geneal Knowledge & 27.494 & $.000^{*}$ & .061 \\
Environmental Action Knowledge & 5.034 & .109 & .012 \\
\hline${ }^{*}$ significant at the level of .05 & & &
\end{tabular}

\subsection{The Differences of Elements in the Construct of Environmental Knowledge Based on Gender}

Table 5 shows the finding of MANOVA analysis for the environmental knowledge elemental differences between male and female students. The finding showed that there are no significant differences between the mean score of environmental knowledge elements as a whole based on gender where the values are Wilks' Lambda $=.998 ; \mathrm{F}(2,425)$ $=.365$ and $p=.695(p>.05)$, partial eta squared $\eta^{2}=.002$. This pattern is similar to the findings of Ismail (2005), Tiwi (2006) and Nor Akhmal (2004) which showed that male and female students are similar in the aspect of environmental knowledge. However, this finding opposes the findings of Kollmuss and Agyeman (2002) and Tikka et al. (2000) that found that the male students have more knowledge compared to female students but female students are more emotional, show more concern towards the environment and have more desire to change (Fadzilah 1999; Kollmuss \& Agyeman 2002; Meinhold \& Malkus 2005; Olofsson \& Ohman 2006; Zamrah 2004). This proved that the cognitive level of male and female students toward the environment is the same mainly due to their similar environment and biological factors that do not influence cognitive level.

Table 5: MANOVA Analysis of Elemental Differences of Environmental Knowledge Based on Gender

\begin{tabular}{lccccccc}
\hline Group & N & Wilks' Lambda Value & F Value & Intergroup df & Intragroup df & Sig. Level & Partial $\eta^{2}$ \\
\hline Male & 200 & .998 & .365 & 2 & 425 & .695 & .002 \\
Female & 228 & & & & & & \\
\hline
\end{tabular}

\subsection{The Differences of Elements in the Construct of Environmental Knowledge Based on Tribe}

Table 6 shows the finding of MANOVA analysis for environmental knowledge elemental differences between students of different tribe. The study finding showed that there are significant differences between the mean score of environmental knowledge elements as a whole based on tribe where the values are Wilks' Lambda $=.962 ; \mathrm{F}(2,425)=8.403$ and $p=$ $.000(p<.05)$, partial eta squared $\eta^{2}=.038$.

Table 6: MANOVA Analysis of Elemental Differences of Environmental Knowledge Based on Tribe

\begin{tabular}{lccccccc}
\hline Group & $\mathbf{N}$ & Wilks' Lambda Value & F Value & Intergroup df & Intragroup df & Sig. Level & Partial $\eta^{2}$ \\
\hline Proto Malay & 196 & .962 & 8.403 & 2 & 425 & .000 & .038 \\
Senoi and Negrito & 232 & & & & & & \\
\hline
\end{tabular}

After obtaining the significant result in the multivariate test, the test of between-subject effects table was referred and the analysis result showed repeated comparison analysis. To reduce Error Type 1 which is due to repeated analysis, Alpha Bonferroni modification method was used (Hair et al. 1998). Table 7 shows the value of $F$, significant (p) and partial eta squared $\left(\mathrm{n}^{2}\right)$ for all the elements of environmental knowledge which are environmental general knowledge and environmental action knowledge. From that table, there is significant difference based on the Alpha Bonferroni (.05/2) = .025 levels of the element of environmental general knowledge and environmental action knowledge based on different tribes. For the element of environmental general knowledge, the values are $F=12.981, p=.000$, partial eta squared $\left(\eta^{2}\right)$ $=.030$, meanwhile for the element of environmental action knowledge, $F=10.255, p=.001$, partial eta squared $\left(\eta^{2}\right)=$ 
Table 7: Intergroup Test Finding of Effect of Tribe on the Elements in the Construct of Environmental Knowledge

\begin{tabular}{lccc}
\hline Elements in the Construct of Knowledge & F Value & Sig. Level $(\boldsymbol{p})$ & Partial $\boldsymbol{\eta}^{\mathbf{2}}$ \\
\hline Environmental General Knowledge & 12.981 & $.000^{*}$ & .030 \\
Environmental Action Knowledge & 10.255 & $.001^{*}$ & .024 \\
\hline${ }^{*}$ significant at the level of .05 & & &
\end{tabular}

Based on the mean score found that Proto Malay tribe students (mean score $=62.86 \%$ ) have a higher level of environmental general knowledge compared to students of Senoi and Negrito tribe (mean score $=55.34 \%$ ). It is also similar for the level of environmental action knowledge; the Proto Malay students (mean score $=80.83 \%$ ) have a higher level of environmental action knowledge compared to students of Senoi and Negrito tribe (mean score $=74.69 \%$ ). This is because the lifestyle of the Proto Malay tribe is more similar to Malay based on the physical, language and cultural characteristics (Zalizan et al. 2009) and they are more developed compared to other tribes. Better developed lifestyle and facilities available in the residential area of the Proto Malay tribe contribute toward the increase in environmental knowledge. This is corresponding with the opinion of Kollmuss \& Agyeman (2002) that facilities in environmental management such as recycle bin, economical factor, social influence and information resources can affect knowledge and behaviour of an individual towards the environment.

\section{Implication and Suggestion}

Based on this research, there are a few suggestions made to increase environmental knowledge among Aboriginal students and thus it is hoped that it will increase their awareness and behaviour of students in nurturing the environment. Among the suggestions that need to be given attention is the role of teachers in increasing students' environmental knowledge. Teachers need to plan their strategies of teaching Environmental Education which is more like fun-learning. Teachers also should be expert in utilizing teaching methods which are creative and suitable to the Aboriginal students such as outdoor learning, hands-on learning, experimental learning, role-play learning, simulation learning and activitybased learning. This is because these learning methods provide opportunities for students to apply what they learned in reality and more interesting, suitable with the character of students who can easily feel bored during learning.

Teachers should emphasize the basic concept of Science among the students because the environmental knowledge has a greater relationship with Science education compared to other subjects. Teachers who are in nonScience field should work together with Science teachers to understand the concept of environment which is related to Science. Teaching and learning in Environmental Education together with environmental awareness programs will be more effective if the concept of environmental science which is being taught in schools is combined with indigenous knowledge which already exist among the Aboriginals. Therefore, ethno biologists should collaborate with environmentalist in planning environmental programs especially for Aboriginal communities and students.

The development of teaching and learning modules for Environmental Education also could assist Aboriginal students in acquiring knowledge and skills in acting positively towards the environment. Learning modules which are more structured and simple helps the Aboriginal students in learning about the environment and at the same time could increase their achievement in other academic fields.

The school administration should be active in implementing environmental awareness programs consistently and more attractively such as bringing students to visit recreational placed which are related to the environment, making compose fertilizer, handicraft demonstration or competition using recycle things and singing or games related to the environment. The school administration also should participate in Sustainable School program to educate their students to love the environment and translate it with an environment-friendly school environment.

Apart from that, other parties also should play their role in increasing environmental knowledge among Aboriginal students such as Ministry of Education Malaysia, parents and Department of Orang Asli Development (DOAD). Ministry of Education Malaysia should provide special Environmental Education courses for teachers to serve as a guide for teachers in planning teaching to combine educational contents of Environmental Education. Parents should cultivate the spirit of loving the environment at home and pass down their indigenous knowledge on environmental management to their children. DOAD on the other hand, should play its role in providing and increasing facilities to access information and communication line such as internet, television and radio in the residential areas of the Aboriginals. This will enable the Aboriginals in finding information and increase their knowledge about the environment which will elevate their level of 
knowledge and behaviour towards the environment.

\section{Summary}

Knowledge is the basis of developing environmentally aware individuals. Environmental knowledge among the Aboriginal students should be increased in order to develop individuals who have ethical awareness and behaviour towards the environment. The change in lifestyle experienced by the Aboriginals needs a friendlier way of thinking and acting so that they are not easily exploited by parties with personal interest and maintain their harmony with the environment. Therefore, all the stakeholders should play their roles in increasing and maintain environmental knowledge among the younger generation of Aboriginals so that the natural treasure is protected in line with the nation's development.

\section{References}

Anderson, M.W., Teisl, M., Criner, G., Tisher, S., Smith, S., Hunter, M., Norton, S.A., Jellison, J., Alyokkin, A., Galland, T.E., Haggard, S. \& Bicknell, E. (2007). Attitude changes of undergraduate university students in general education courses. The Journal of General Education 56: 149-158.

Chopil, T.Y \& Hunt, B.T.W. (2009). Aboriginals and Environment. Retrieved March 2010, from www.perakspeak.com.

Elder, J. L. (2003). A Field Guide to Environmental Literacy: Making Strategic Investment in Environmental Education. Environmental Education Coalition.

Emmons, K.M. (1997) Perspectives on environmental action: Reflection and revision through practical experience. The Journal of Environmental Education 29,1: 34-44.

Haliza Abdul Rahman. (2010). The Involvement of Aboriganal Community in Issues Related to the Environment: Survey on Mah Meri Pulau Carey, Kuala Langat, Selangor. Kemanusiaan 17 : 114-134.

Hines, J.M., Hungerford, H.R. \& Tomera, A.N. (1986/87). Analysis and synthesis of research on responsible environmental behaviour: A meta-analysis. Journal of Environmental Education 18, 2: 1-8.

Hood Salleh (2012). Dignifying the Aboriginal Research in Malaysia. ISBN: 9789674121006.

Tun Seri Lanang Lecture on 16 October. Bangi: National University of Malaysia Publisher.

Hungerford, H.R., Bluhm, W.J., Volk, T.L., \& Ramsey, J.M. (2005). The Tbilisi Declaration. Essential Readings in Environmental Education.3rd Edition. Champaign, Illinois: Stripes Publishing.

Ismail bin Hussin. (2005). The level of environmental awareness among the secondary school students of Jerantut district, Pahang. Master Research Project. National University of Malaysia

Department of Orang Asli Development (DOAD) (2009). Retrieved February 2010, from jheoa.gov.my

Kollmuss, A. \& Agyeman, J. (2002). Mind The Gap: Why Do People Act

Environmentally And What Are The Barriers To Environmental Behavior? Environmental Educational Research 8, 3: 239-260.

Krejcie, R.V. \& Morgan, D.W.(1970) Determining Sample Size for Research Activities. Educational And Pcychological Measurement 30: 607-610.

Lim Hwei Mian (1997) Nutritional Status and Reproductive Health of Orang Asli Women. Master Research Project. Serdang: University Putra Malaysia.

Mallen, I. R., Barrazab, L., Bodenhornc, B., \& Garcia, V. R. (2009) School and local environmental knowledge, what are the links? A case study among indigenous adolescents in Oaxaca, Mexico. International Research in Geographical and Environmental Education 18, 2: 82-96.

Mohd. Yusop bin Ab. Hadi, Jailani bin Mohd. Yunos \& Ahmad bin Esa. (2003) Increasing the knowledge, practice and attitude towards environmental education among students. National Seminar Proceeding of Environmental Managemant. Bangi: National University of Malaysia.

Nicholas, C. \& Lasimbang, J. (2004) Biodiversity \& Indegenous Knowledge System in Malaysia. Subang Jaya: Centre for Orang Asli Concern.

Nor Akhmal Ismail. (2004) Awareness of students about the Environmental Education (EE) in the Geography curriculum. Master Research Project. University of Malaya.

Norjan Yusuf, Nur Ibtisam Ibrahim, Rohana Sulaiman \& Rohayati Mamat. (2005) Survey on the environmental knowledge and awareness among Aboriginal students: National Seminar Proceeding of Environmental Managemant. Bangi: National University of Malaysia.

Palmer, J.A. (1998) History and development of Environmental Education. Environment Education in the 21st century. theory, practice, progress and promise. London: New Fatter Lane.

Quimby, J. L., Seyala, N. D., Wolfson, J. L. (2007) Social Cognitive Predictors Of Interest In

Environmental Science: Recommendations For Environmental Educators. The Journal Of Environmental Education 38, 3: 43-52.

Ramsey, C.E., \& Rickson, R.E. (1976). Environmental knowledge and attitudes. The Journal of Environmental Education 8, 11, 10-18.

Stapp, W.B. (1969) The concept of environmental education. The Journal of Environmental Education 1,1: 30-31.

Sheppard, J. A. C. (1995) The black - white environmental concern gap: An examination of environmental paradigms. The Journal of 
Environmental Education 26, 24-35.

Tikka, P.M., Kuitunen, T.M., \& Tynys, S. M. (2000) Effects of educational background on students' attitudes, activity levels, and knowledge concerning the environment. Journal of Environmental Education 31, 3, $12-19$.

Tiwi Kamidin. (2006) The relationship between knowledge \& attitude towards the environment

among trainee teachers in Batu Lintang Teacher Training Institute. Retrieved February 2008, from http://www.mpbl.edu.my/inter /penyelidikan/jurnalpapers/jurnal2006/tiwi06b

United Nations. (1992) Agenda 21 chapter 36. Retrieved January 2008, from http://www.un-documents.net/a21-36.htm.

Zalizan Mohd Jelas, Abdul Razaq Ahmad \& Ahmad Rafaai Ayudin. (2009) The

Perspective of Aboriginal Historiology in Peninsular Malaysia. In. The Aboriginal Community: Educational and Sociocultural Perspectives. Bangi: National University of Malaysia. 